\title{
Initial computed tomography features of known inpatient ward versus intensive care admission COVID-19 cases: is there any difference?
}

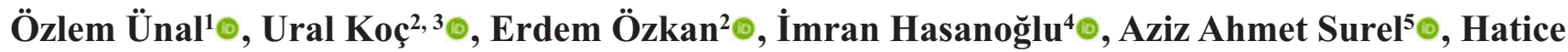 \\ Rahmet Güner ${ }^{4,6} \odot$
}

${ }^{1}$ Department of Radiology, Ankara Ylldırım Beyazıt University, Ankara City Hospital, Ankara, Turkey

${ }^{2}$ Department of Radiology, Ankara City Hospital, Ankara, Turkey

${ }^{3}$ General Directorate of Health Services, The Turkish Ministry of Health, Ankara, Turkey

${ }^{4}$ Department of Infectious Diseases, Ankara Yıldırım Beyazıt University, Ankara City Hospital, Ankara, Turkey

${ }^{5}$ Coordinator Head Physician, Ankara City Hospital, Ankara, Turkey

${ }^{6}$ COVID-19 Advisory Committee of the Ministry of Health of Turkey, Ankara, Turkey

\begin{abstract}
Objectives: The aim of this study was to evaluate initial computed tomography (CT), basic clinical and demographic features of cases with COVID-19 pneumonia with known inpatient ward and intensive care unit hospitalization.

Methods: A total of 200 cases (103 males, 97 females; age range: 18-92 years) were retrospectively and randomly collected whom were hospitalized and followed up at infectious disease inpatient ward and intensive care unit (ICU). The initial CT findings were interpreted by two radiologists at the same session by consensus. Results: Cough (61\%) and fever (54\%) were the main symptoms at the onset presentation. Initial chest CT imaging revealed that $79.5 \%$ ground-glass opacities. Bilateral distribution $(62.5 \%)$, peripheral and central distribution (45.5\%), dorsal and ventral involvement $(52.5 \%)$ were identified in all cases. CT features predominantly were at right and left lower lobes $(69.5 \%, 62.5 \%$; respectively). Cases with known ICU admission had statistically significant differences with inpatient ward admission cases in regards to CT features included mixed GGO and consolidation, bronchial wall thickening, pleural effusion, subpleural band, emphysema, coronary calcification, cardiothoracic ratio, aorta diameter.

Conclusions: Initial CT features may be helpful for foreseeing admission to ICU as in clinical features.

Keywords: COVID-19, CT, ICU, inpatient, features
\end{abstract}

$\mathrm{C}$ oronavirus 2019 disease (COVID-19) was officially named by the World Health Organization (WHO) on 11 February, 2020 after cases of pneumonia unknown etiology was identified in Wuhan, China in December 2019 [1,2]. The novel coronavirus (2019-nCoV) was isolated by Chinese authorities on 7 January, 2020 [1]. On 11 March, 2020 WHO an- nounced COVID-19 as a pandemia [3], on the other hand The Ministry of Health, Turkey reported first laboratory-confirmed novel coronavirus (2019-nCoV) case on 10 March, 2020 [4]. By May 31, 2020, a total of 163,942 confirmed cases, $2.77 \%$ case fatality rate, 648 critical or serious ICU follow-up cases have been reported in Turkey at daily official announcement [4, 
5].

Reverse transcription-polymerase chain reaction (RT-PCR) is the gold standart diagnostic method for COVID-19, however high false-negative results make managing difficulties in disease course. At this point, radiological methods such as chest x-ray and computed tomography (CT) play important role and are helpful for clinicians in both supporting diagnosis and monitoring the cases even if PCR is negative, but COVID-19 is highly clinically suspected $[6,7]$. CT imaging findings of laboratory-confirmed COVID-19 cases in detail from many countries, mainly from China, were to be reported as small or large case sample series $[8,9]$.

Older adults and cases with concomitant diseases such as hypertension are at a significant risk of severe outcome related to COVID-19 disease [10, 11]. CT has not only pivotal role in the diagnosis, but also has significant role on management of temporal changes of the disease both clinically and radiologically [12]. In this point of view, we hypothesized if there was a difference between initial CT manifestations with known inpatient ward or intensive care unit (ICU) hospitalization history.

In this study, we aimed to evaluate and compare the initial CT, basic clinical and demographic features of laboratory-confirmed sample of 200 COVID-19 cases with known inpatient ward and ICU admission in Ankara City Hospital, Turkey.

\section{METHODS}

Turkish Ministry of Health approval was obtained on 21 May, 2020 and local ethics committee approval was received from Ankara City Hospital Ethical Committee, Turkey (approved number: E1/666/2020) on 28 May, 2020. Informed consent was waived due to the retrospective nature of this study.

\section{Cases}

A total of 1,800 cases with laboratory-confirmed COVID-19, 5500 highly clinically suspected cases who were admitted to Ankara City Hospital in Turkey from March 11, 2020 to May 31, 2020. As a sample 200 laboratory-confirmed COVID-19 cases were retrospectively and randomly collected who were hospitalized and followed up at infectious disease inpatient ward and ICU. The study included 103 males and 97 females with a median age of 45 years (range, 18-92). The basic demographic, clinical and radiological data including gender, age, exposure history, onset symptoms, underlying diseases, CT features were screened, interpreted and analyzed. The study sample had at least one positive results of RT-PCR with nasopharyngeal swab testing and chest CT examination in their electronic health records. Chest CT examinations and admissions were at the same day for study sample. Flow chart of the study was shown in Fig. 1.

\section{Imaging Technique}

The chest $\mathrm{CT}$ examinations were acquired by using 128-slice Revolution Evo CT (GE Healthcare) scanners in the supine position at full inspiration from lung apices to the inferior level of the costophrenic angle. The acquisition parameters were as follows: 100 or $120 \mathrm{kVp}$; $80-400 \mathrm{mAs}$; 1.375 , pitch; 0.625 reconstruction interval; 0.5 seconds (sec) rotation time. Slice thickness was $1.25 \mathrm{~mm}$. Automatic exposure control system (ASiR, GE, Healthcare) regulated the tube current. All chest $\mathrm{CT}$ examinations were obtained without intravenous contrast material.

\section{Imaging Interpretation}

The chest CT examinations were reviewed at the picture archiving and communication systems (PACS) by two radiologist blinded to the radiology report and clinic data at the same session by consensus. The conventional lung and mediastinal window settings were used by radiologists (window width: 1500 hounsfield unit (HU), window level: -600 to $-700 \mathrm{HU}$; window width: 350-450 hounsfield unit (HU), window level: 40-50 HU, respectively). Multiplanar reconstruction (MPR) techniques were also used at the image interpretation sessions.

The chest $\mathrm{CT}$ features were interpreted in the view of presence of CT features, number of lung lobes involved, frequency of lung lobe involvement, lesion distribution by side (bilateral or unilateral), anteriorposterior localisation (ventral, dorsal or both), transverse localisation (central, peripheral or both) and scattering (focal, multifocal or diffuse), lesion characteristics and other findings. We evaluated lesion characteristics defined in previous studies and in accordance with glossary of Fleischner Society [13$16]$. We measured main pulmonary artery and aorta di- 


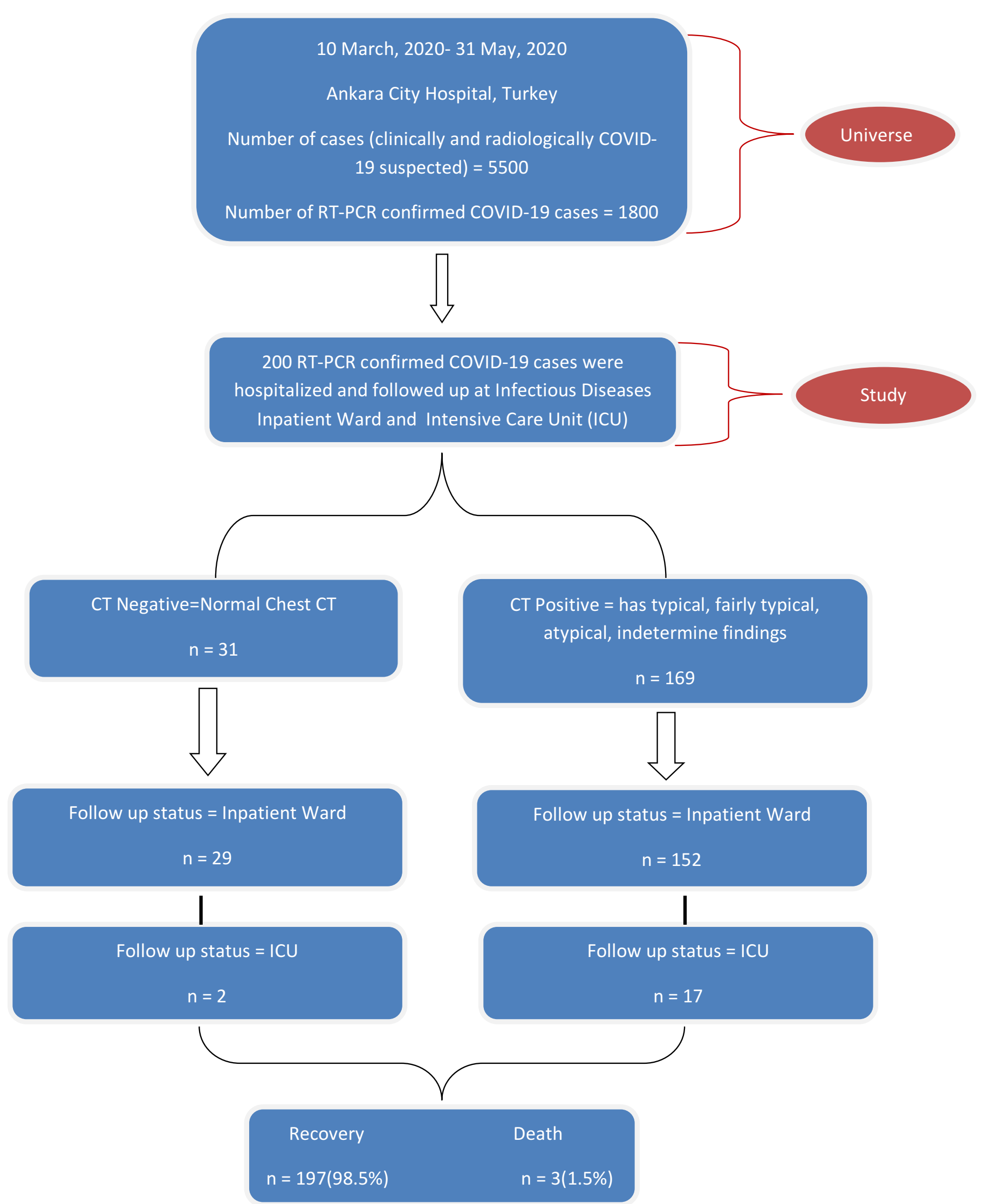

Fig. 1. Flow chart of the study. 


\section{Table 1. Basic demographic and clinical features}

\begin{tabular}{|c|c|}
\hline Features & $\begin{array}{c}\text { All Cases } \\
(n=200)\end{array}$ \\
\hline \multicolumn{2}{|l|}{ Sex } \\
\hline Male & $103(51.5)$ \\
\hline Female & $97(48.5)$ \\
\hline \multicolumn{2}{|l|}{ Age (years) } \\
\hline Median & 45 \\
\hline Range & $18-92$ \\
\hline \multicolumn{2}{|l|}{ Age group (years) } \\
\hline $18-29$ & $31(15.5)$ \\
\hline $30-39$ & $47(23.5)$ \\
\hline $40-49$ & $39(19.5)$ \\
\hline $50-59$ & $33(16.5)$ \\
\hline $60-69$ & $20(10)$ \\
\hline$>69$ & $30(15)$ \\
\hline \multicolumn{2}{|l|}{ Exposure history } \\
\hline Exposure & $98(49)$ \\
\hline No exposure & $102(51)$ \\
\hline \multicolumn{2}{|l|}{ Onset symptoms ${ }^{\mathrm{a}}$} \\
\hline Time since symptoms onset (day) & $3(0-10)$ \\
\hline Cough & $122(61)$ \\
\hline Fever & $108(54)$ \\
\hline Dyspne & $59(29.5)$ \\
\hline Myalgia & $55(27.5)$ \\
\hline Malasie/Debility & $57(28.5)$ \\
\hline Headache & $33(16.5)$ \\
\hline Anosmia & $20(10)$ \\
\hline Loss of taste & $11(5.5)$ \\
\hline Diarrhea & $9(4.5)$ \\
\hline Chest Pain & $5(2.5)$ \\
\hline Back pain & $2(1)$ \\
\hline No symptoms & $39(19.5)$ \\
\hline \multicolumn{2}{|l|}{ Underlying disease $^{\mathrm{b}}$} \\
\hline Hypertension & $45(22.5)$ \\
\hline Coronary artery disease & $36(18)$ \\
\hline Diabetes & $25(12.5)$ \\
\hline Chronic obstructive pulmonary disease & $15(7.5)$ \\
\hline Others (Asthma,CKD ${ }^{\mathrm{c}}, \mathrm{PAD}^{\mathrm{d}}$, Alzeimer) & $5(2.5)$ \\
\hline None & $142(71)$ \\
\hline
\end{tabular}

Note-Except for age and time since symptoms onset (median with minimum-maximum range) data are numbers with percentage in parentheses.

${ }^{\mathrm{a}, \mathrm{b}}$ Some cases had more than one symptoms and underlying disease.

${ }^{\mathrm{c}, \mathrm{d}}$ Chronic kidney disease, peripheral artery disease ameters at the level of the bifurcation of the main pulmonary artery in the transverse plan. Cardiothoracic ratio assessed as maximum diameter of heart divided by maximum thoracic diameter in the axial CT images of chest. Coronary calcifications, scoliosis and kyphosis were interpreted via MPR images as present or absent.

\section{Statistical Analysis}

Categorical and nominal datas were presented as numbers and percentages, numeric datas as medians with minimum-maximum range. Comparison of categoric and nominal datas was evaluated by chi-square or Fisher exact test, on the other hand numeric datas by Mann Whitney $U$ test between inpatient ward and ICU admission cases. $P$ value $<0.05$ was accepted as statistically significant. SPPS for Windows software package (version 21.0, SPSS Inc.) was used for statistical analysis.

\section{RESULTS}

\section{Demographic and Clinical Features}

A total of 200 cases were included in this study. Our group of cases consisted of 103 (51.5\%) males, 97 (49.5\%) females, with an age range of 18-92 (median age, 45 years). $41.5 \%$ of total cases were older than 50 years. The time between onset of symptoms and hospital presentation ranged from 0 to 10 days (median, 3 days). 49\% $(\mathrm{n}=98)$ of total cases had an exposure history to patients with laboratory confirmed COVID-19. Common onset symptoms were cough $(61 \%)$ and fewer (54\%). Thirty-nine cases had no symptoms. The basic demographic and clinical features are given in Table 1.

\section{Initial CT Features}

Thirty-one cases $(15.5 \%)$ had normal CT without any findings. Five lobes involvement were identified $38.5 \%(n=77)$ of total cases. Right and left lower lobes were more likely to be involved (69.5\% versus $62.5 \%$ ). Lesion distribution characteristics in lung parenchyma are given in Table 2. Typical features such as ground-glass opacities (GGOs) $(79.5 \%)$, roundshaped lesions (44\%) and vascular enlargement (38\%) were presented on the CT images in most of the cases (Figs. 2 and 3). Reversed halo sign and crazy-paving 

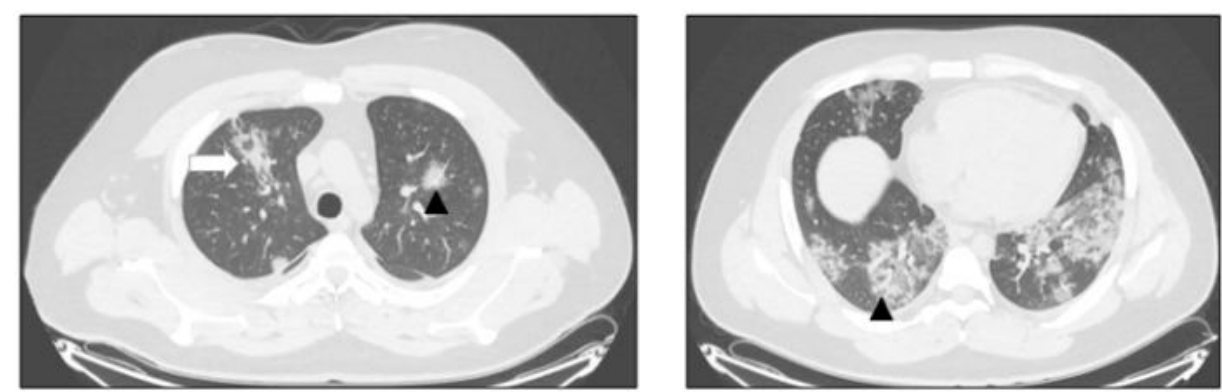

A
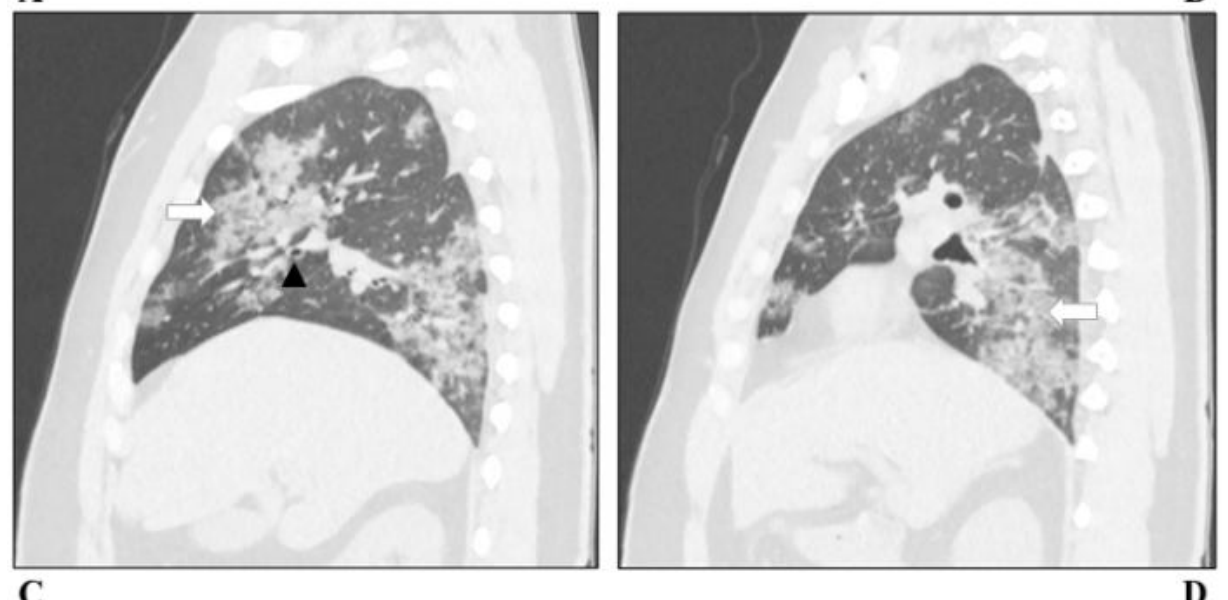

Fig. 2. (A-D) A 55-year-old man with coronavirus disease (COVID-19). Patient had onset symptoms of fever, cough and dyspnea. CT was performed on day of admission. CT images show bilateral multifocal ground-glass opacities (GGOs) and GGOs with superimposed consolidations (white arrows: A, C and D). Vascular enlargements and bronchial wall thickenings (black arrowheads: A, B, C) are also present.
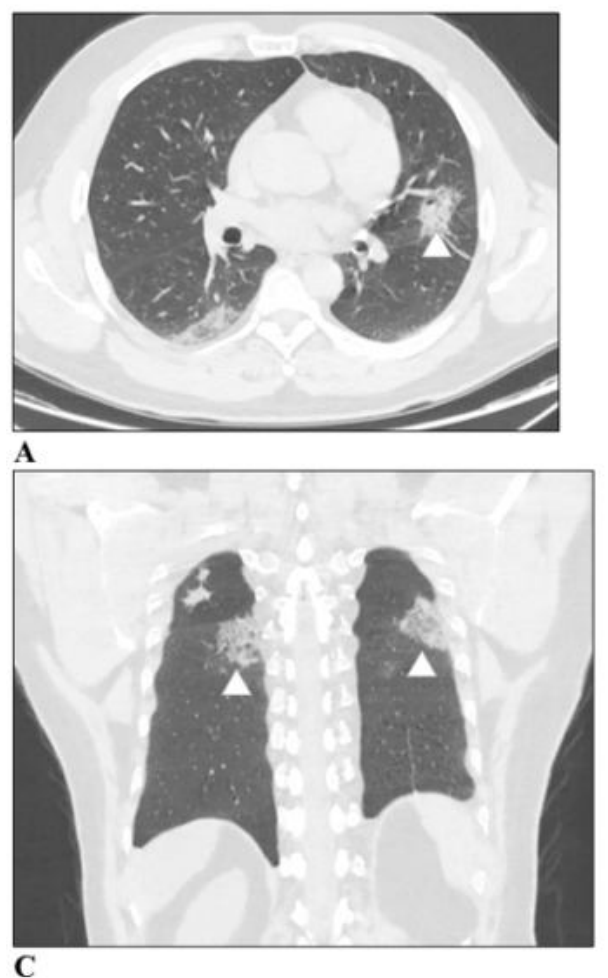
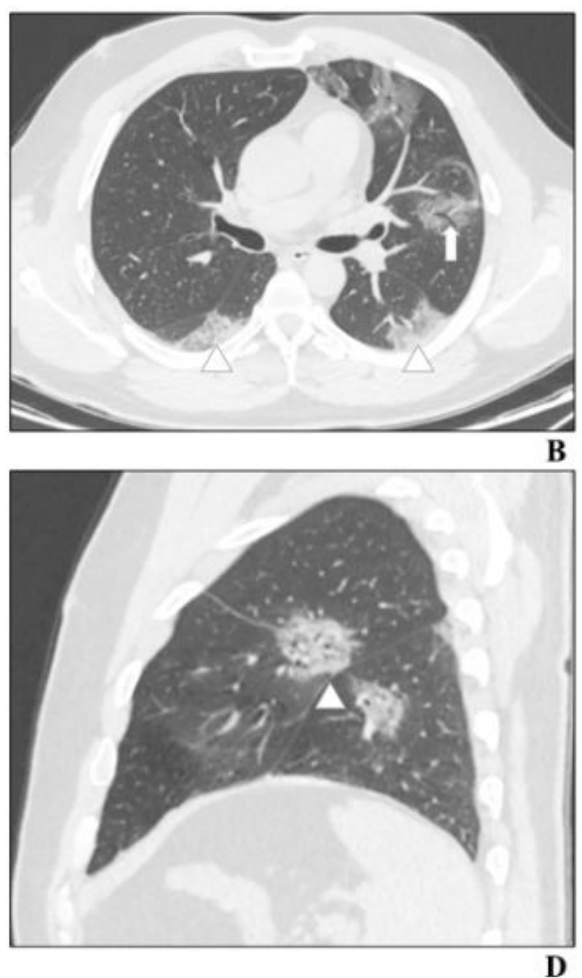

Fig. 3. (A-D) A 45-year-old man with cough. Axial (A and B), coronal (C) and sagittal (D) CT images show bilateral multiple ground-glass opacities (GGOs) and consolidations with thickened intralobular and interlobular septum (white arrowheads: A, C and D). Air bronchogram sign is also present (white arrow: B). 


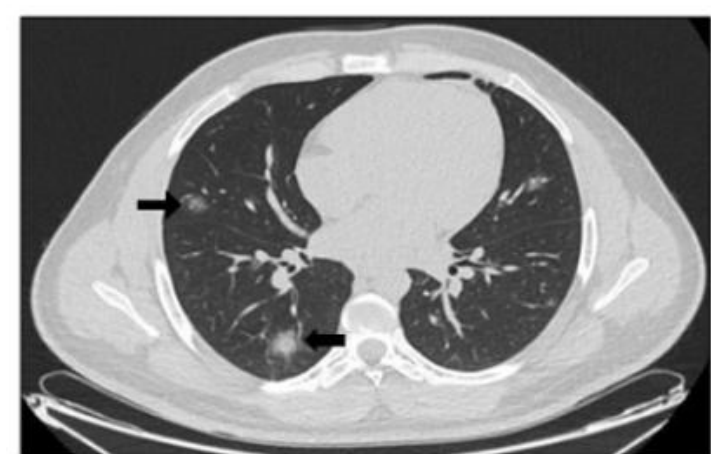

A

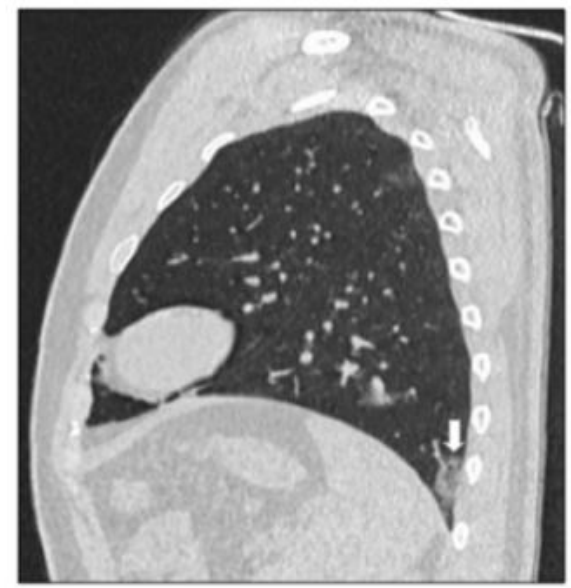

C

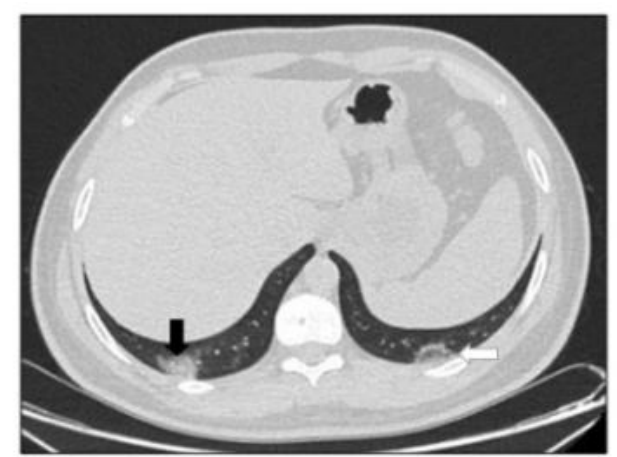

B

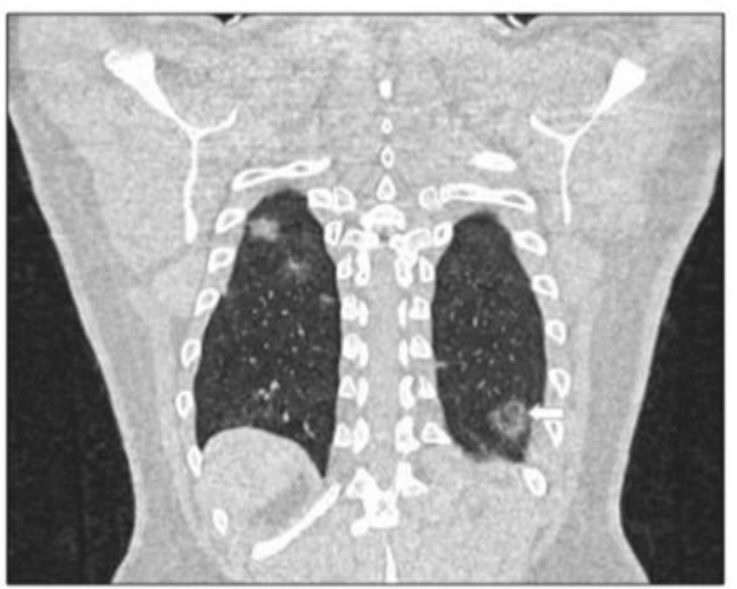

D

Fig. 4. (A-D) A 38-year-old man with laboratory confirmed coronavirus disease (COVID-19). Patient presented with fever and cough for two days. CT was performed on day of admission. Axial CT images show peripheral round-shaped groundglass opacities(GGOs) (black arrows: $A$ and B). Reverse halo sign is also present in axial, sagittal and coronal images (white arrows: B, C and D).

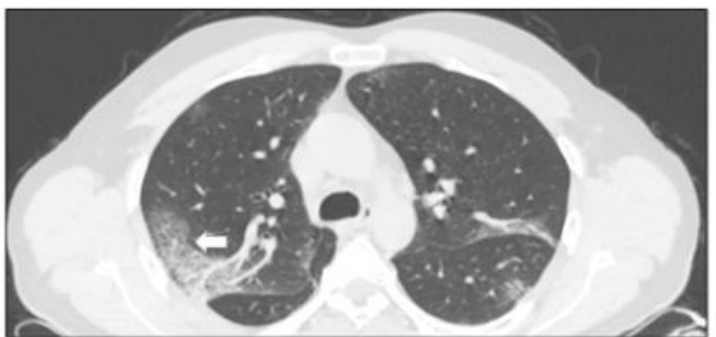

A

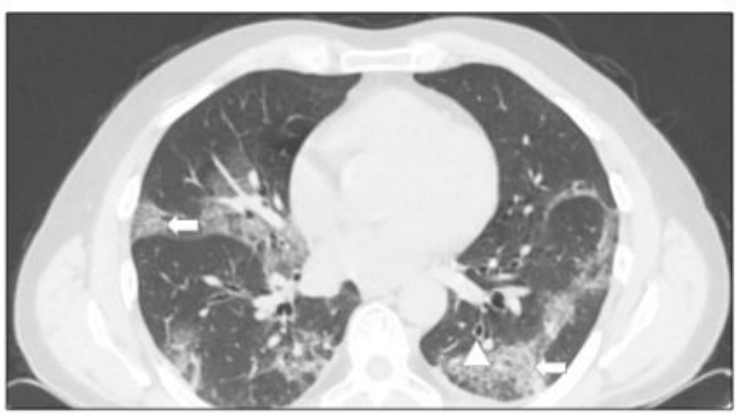

C

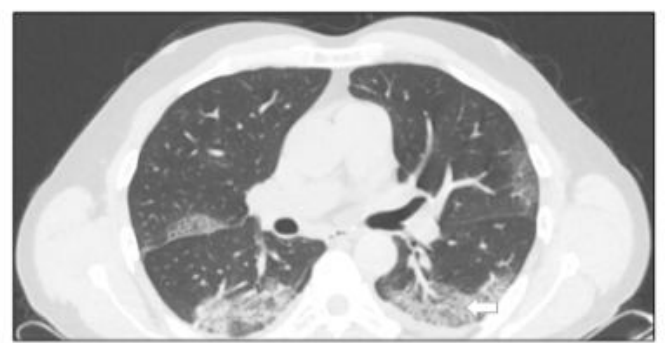

B

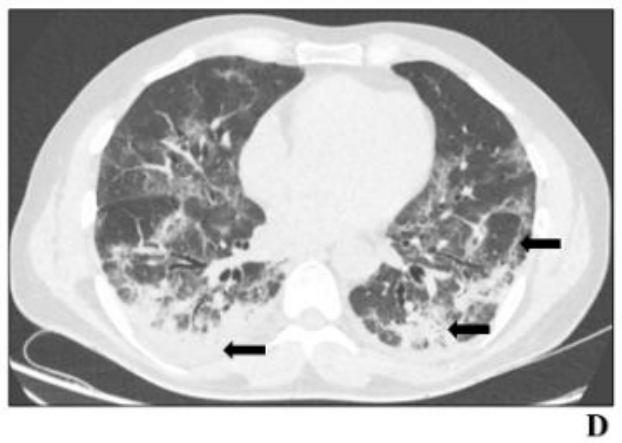

D

Fig. 5. (A-D) A 60-year-old man with dry cough, dyspnea and fatigue. CT was performed on day of admission (A, B and C) and 10 days later (D). Axial CT scans show interlobular septal thickening in a crazy paving pattern (white arrows: A, B and C) and bronchial wall thickening (white arrowhead: C), while consolidations and subpleural curvilinear bands occur10 days later (black arrows: D). 
Table 2. Other chest CT features and measurements

\begin{tabular}{|c|c|c|c|c|}
\hline Findings & $\begin{array}{l}\text { All Cases } \\
(n=200)\end{array}$ & $\begin{array}{c}\text { Cases followed-up } \\
\text { inpatient ward } \\
(n=181) \\
\end{array}$ & $\begin{array}{c}\text { Cases with ICU } \\
\text { admission } \\
(\mathbf{n}=19) \\
\end{array}$ & p value \\
\hline Age (years) & $45(18-92)$ & $43(18-92)$ & $72(36-92)$ & $<0.001$ \\
\hline Sex & & & & 0.705 \\
\hline Male & $103(51.5)$ & $94(51.9)$ & $9(47.4)$ & \\
\hline Female & $97(48.5)$ & $87(48.1)$ & $10(52.6)$ & \\
\hline Underlying disease & $58(29)$ & $39(21.5)$ & $19(100)$ & $<0.001$ \\
\hline Without CT findings (\%) & $31(15.5)$ & $29(16)$ & $2(10.5)$ & 0.744 \\
\hline Time since symptoms onset (day) & $3(0-10)$ & $3(0-10)$ & $0(0-8)$ & 0.006 \\
\hline \multicolumn{5}{|l|}{ Imaging Findings } \\
\hline Number of lobes involved & & & & 0.520 \\
\hline 1 & $38(19)$ & $33(18.2)$ & $5(26.3)$ & \\
\hline 2 & $21(10.5)$ & $18(9.9)$ & $2(10.5)$ & \\
\hline 3 & $12(6)$ & $12(6.6)$ & $1(5.3)$ & \\
\hline 4 & $21(10.5)$ & $19(10.5)$ & $2(10.5)$ & \\
\hline 5 & $77(38.5)$ & $70(38.7)$ & $7(36.8)$ & \\
\hline \multicolumn{5}{|l|}{ Frequency of lobe involvement } \\
\hline Right upper lobe & $108(54)$ & $99(54.7)$ & $9(47.3)$ & 0.542 \\
\hline Left upper lobe & $107(53.5)$ & $99(54.7)$ & $8(42.1)$ & 0.295 \\
\hline Middle lobe & $104(52)$ & $95(52.5)$ & $9(47.3)$ & 0.671 \\
\hline Right lower lobe & $139(69.5)$ & $127(70.2)$ & $12(63.1)$ & 0.528 \\
\hline Left lower lobe & $125(62.5)$ & $113(62.4)$ & $12(63.1)$ & 0.950 \\
\hline Lung region distribution & & & & 0.564 \\
\hline Bilateral & $125(62.5)$ & $111(61.3)$ & $14(73.7)$ & \\
\hline Unilateral & $44(22)$ & $41(22.7)$ & $3(15.8)$ & \\
\hline Transverse distribution & & & & 0.483 \\
\hline Central & $4(2)$ & $3(1.7)$ & $1(5.3)$ & \\
\hline Peripheral & $74(37)$ & $67(37.0)$ & $7(36.8)$ & \\
\hline Peripheral and central & $91(45.5)$ & $82(45.3)$ & $9(47.4)$ & \\
\hline Anterior-posterior distribution & & & & 0.618 \\
\hline Ventral & $12(6)$ & $11(6.1)$ & $1(5.3)$ & \\
\hline Dorsal & $52(26)$ & $45(24.9)$ & $7(36.8)$ & \\
\hline Ventral and dorsal & $105(52.5)$ & $96(53.0)$ & $9(47.4)$ & \\
\hline Scattered distribution & & & & 0.019 \\
\hline Focal & $38(19)$ & $32(17.7)$ & $4(21.1)$ & \\
\hline Multifocal & $115(57.5)$ & $108(59.7)$ & $9(47.4)$ & \\
\hline Diffuse & $16(8)$ & $12(6.6)$ & $4(21.1)$ & \\
\hline Round-shaped lesions & $88(44)$ & $82(45.3)$ & $6(31.6)$ & 0.144 \\
\hline Ground-glass opacities & $159(79.5)$ & $146(80.7)$ & $13(68.4)$ & 0.010 \\
\hline Consolidation & $60(30)$ & $52(28.7)$ & $8(42.1)$ & 0.294 \\
\hline $\begin{array}{l}\text { Mixed ground-glass opacities } \\
\text { and consolidation }\end{array}$ & $57(28.5)$ & $49(27.1)$ & $8(42.1)$ & $<0.001$ \\
\hline Reticulation & $59(29.5)$ & $52(28.7)$ & $7(36.8)$ & 0.568 \\
\hline Centrilobular nodules & $17(8.5)$ & $14(7.7)$ & $3(15.7)$ & 0.385 \\
\hline Crazy-paving pattern & $43(21.5)$ & $39(21.5)$ & $4(21.1)$ & 0.848 \\
\hline Air bronchogram sign & $27(13.5)$ & $24(13.3)$ & $3(15.7)$ & 0.738 \\
\hline Bronchiectasis & $15(7.5)$ & $12(6.6)$ & $3(15.7)$ & 0.179 \\
\hline Bronchial wall thickening & $17(8.5)$ & $11(6.1)$ & $6(31.6)$ & 0.003 \\
\hline Reversed halo sign & $15(7.5)$ & $15(8.3)$ & $0(0)$ & 0.368 \\
\hline Halo sign & $26(13)$ & $26(14.4)$ & $0(0)$ & 0.078 \\
\hline Subpleural bands & $17(8.5)$ & $11(6.1)$ & $6(31.6)$ & 0.003 \\
\hline Vascular enlargement & $76(38)$ & $68(37.6)$ & $8(42.1)$ & 0.697 \\
\hline Pleural effusion & $5(2.5)$ & $0(0)$ & $5(26.3)$ & $<0.001$ \\
\hline Pleural thickening & $7(3.5)$ & $5(2.8)$ & $2(10.5)$ & 0.148 \\
\hline Mediastinal lymphadenopathy & $40(20)$ & $32(17.7)$ & $7(36.8)$ & 0.073 \\
\hline Pericardial effusion & $11(5.5)$ & $8(4.4)$ & $3(15.7)$ & 0.084 \\
\hline Cavitation & $0(0)$ & $0(0)$ & $0(0)$ & \\
\hline Pneumothorax & $0(0)$ & $0(0)$ & $0(0)$ & \\
\hline Empyhsema & $33(16.5)$ & $26(14.4)$ & $7(36.8)$ & 0.021 \\
\hline Coronary calcification & $55(27.5)$ & $44(24.3)$ & $11(57.9)$ & 0.002 \\
\hline Scoliosis & $47(23.5)$ & $37(20.4)$ & $10(52.6)$ & 0.004 \\
\hline Kyphosis & $57(28.5)$ & $43(23.8)$ & $14(73.7)$ & $<0.001$ \\
\hline Main pulmonary artery diameter (mm) & $26.5(18-43)$ & $26(18-43)$ & $28(20-34)$ & 0.352 \\
\hline Aorta diameter $(\mathrm{mm})$ & $31(21-45)$ & $31(21-43)$ & $34(25-45)$ & 0.006 \\
\hline Cardiothoracic ratio & $0.45(0.23-0.66)$ & $0.45(0.23-0.66)$ & $0.52(0.43-0.63)$ & $<0.001$ \\
\hline
\end{tabular}

Note-Except for age, main pulmonary artery, ascending aorta diameter and cardiothoracic ratio (median with minimum-maximum range) data are numbers with percentage in parentheses. 
patern were identified 7.5\% $(\mathrm{n}=15)$ and $21.5 \%(\mathrm{n}=$ 43) of total cases, respectively (Figs. 4 and 5). Other chest $\mathrm{CT}$ features and measurements are demonstrated in Table 2.

Comparison of Basic Demographic-Clinical and Initial CT Features with Known Inpatient Ward and ICU Admission Cases

Cases with known ICU admission were older than known inpatient ward admission $(p<0.001)$. All of the cases known ICU admission had comorbid diseases. There were statistically significant difference the time between onset of symptoms and hospital presentation ( $p=0.006$ ). Regarding to lobe number and frequency of lobe involvement, no significant difference were found between two groups. The anteriorposterior, transverse, lung side distributions had no significant difference, on the other hand in regards to scattered distribution diffuse patern was higher frequency $(21.1 \%)$ in known ICU admission cases. GGOs' were commonly presented in known inpatient ward admission cases $(P=0.01)$, however mixed GGO and consolidations were identified in known ICU admission cases $(p<0.001)$. Other statistically significant and non-significant features and measurements are shown in Table 2.

\section{DISCUSSION}

The purpose of this study was to analyzed initial CT features of patient with known hospitalization in ICU and inpatient ward. An outstanding feature of this study is not only comprehensively evaluated initial CT features but also assessed differences in CT findings between known ICU and inpatient ward admission.

Meta-analyses and systematic reviews revealed that gender and age range varied between different sample sizes, countries [14, 17]. In our study cohort, cases were predominantly male and median age was 45. Most of the cases were under the age of 60 could be related to the statement of curfew restriction for people over the age 65. In their review and metaanalysis of 1115 patients, Won et al. [18] showed that fever and cough were the main clinical characteristics. We found that the similar clinical characteristics, on the other hand anosmia, loss of taste, diarrhea, chest pain and back pain were less frequently seen. 19.5\% of our cases with no symptoms were recurited from filiation method.

In the current study, bilateral, multifocal, periferal and dorsal dominant, five lobes involvement with a lower lobe predominance especially right was the most common lesion localizations. GGOs, roundshaped lesions, vascular enlargement were the main $\mathrm{CT}$ features. These findings are in agreement with previous systematic reviews and meta-analyses $[14,16-$ 18]. The typical findings suggesting that progression including consolidation, mixed GGOs and consolidation, crazy-paving patern, reversed halo sign were found less frequently. On the other hand, of our cases, $\% 15.5$ had normal CT in their initial imaging. These results may be related to accession of cases to healthcare in the early period and filiation method. In our cases, median day for hospital presentation after the symptoms were started, was 3 . The atypical and fairly typical findings, such as bronciectasis, air-brochogram sign, bronchial wall thickening, halo sign, subpleural bands, pleural thickening, pleural effusion, pericardial effusion, centrilobular nodules and lymphadenopathy were also seen but less commonly compatible with previous literature [19]. Cavitation and pneumothorax cases with COVID-19 were rarely reported in literature $[20,21]$. These two rare findings were not seen in our cases.

In their study, Meng et al. [22] reported that main CT feature was GGOs in asymptomatic cases with COVID-19. Our results suggested that same initial CT findings especially cases known inpatient wards admission. However, CT features of diffuse distribution, mixed GGOs and consolidation were statistically significant initial CT finding in known ICU admission cases than known inpatient wards admission. Pure consolidation was higher at initial CTs with known ICU cases, but it was not statistically significant than with known inpatient ward admission. Subpleural bands or lines which may be associated to pulmonary edema or fibrosis and bronchial wall thickening which usually related to inflammation of airways [23], we found these findings higher in their initial CTs with known ICU admission cases. Pleural effusion indicating severity were observed higher in cases with known ICU admission. Other findings, such as pericardial effusion and mediastinal lymphadenopathy suggesting severity [24] showed higher frequencies in their initial CTs with known ICU admission cases, but it was not 
statistically significant.

Older age and comorbidities are major risk factors leading to poor prognosis for patients with COVID$19[25,26]$. In accordance with these factors, in our cohort known ICU admission cases had older median age and underlying diseases which were statistically significant than with known inpatient ward admission. These cases showed early hospital presentation. Moreover, these group of cases had significant findings in regard to $\mathrm{CT}$ features such as emphysema, coronary calcifications, scoliosis, kyposis, aorta diameter and cardiothoracic ratio which were also related to age and underlying diseases. We should give attention these findings at image interperations.

\section{Limitations}

Our study has some limitations. Firstly, we did not evaluate laboratory findings. Secondly, we only interpreted the initial CTs, not follow-up CTs. Liu et al. [27] revealed that $\mathrm{CT}$ quantification of lesion might early predict the progression and severity. Our study was based on predominantly qualitative CT features. Therefore lastly, visual assessments might cause under- or over-estimation some of CT features.

\section{CONCLUSION}

Initial chest $\mathrm{CT}$ imaging features may give an idea whether patients may need intensive care admission in the COVID-19 course like demographic features such as elderly or clinical features such as having hypertension history.

\section{Authors' Contribution}

Study Conception: ÖÜ, UK, EÖ, İH, AAS, HRG; Study Design: ÖÜ, UK, EÖ, İH, AAS, HRG; Supervision: ÖÜ, UK, EÖ, İH, AAS, HRG; Funding: N/A; Materials: ÖÜ, UK, EÖ, İH; Data Collection and/or Processing: ÖÜ, UK, EÖ, İH; Statistical Analysis and/or Data Interpretation: ÖÜ, UK, EÖ, HRG; Literature Review: ÖÜ, UK, HRG; Manuscript Preparation: ÖÜ, UK, EÖ, İH, AAS and Critical Review: İH, AAS, HRG.

\section{Conflict of interest}

The authors disclosed no conflict of interest during the preparation or publication of this manuscript.

\section{Financing}

The authors disclosed that they did not receive any grant during conduction or writing of this study.

\section{REFERENCES}

1. World Health Organization website. Coronavirus disease 2019 (COVID-19) situation report-1. World Health Organization, Geneva. Available via https://www.who.int/docs/defaultsource/coronaviruse/situation-reports/20200211-sitrep-22ncov.pdf?sfvrsn=fb6d49b1_2. Accessed June 01 Jun 2020

2. World Health Organization website. Coronavirus disease 2019 (COVID-19) situation report-22. World Health Organization, Geneva. Available via https://www.who.int/docs/defaultsource/coronaviruse/situation-reports/20200121-sitrep-1-2019ncov.pdf?sfvrsn=20a99c10_4 . Accessed 01 Jun 2020

3. World Health Organization website. Coronavirus disease 2019 (COVID-19) situation report-51. World Health Organization, Geneva. Available via https://www.who.int/docs/defaultsource/coronaviruse/situation-reports/20200311-sitrep-51-covid19.pdf?sfvrsn=1ba62e57_10. Accessed 01 Jun 2020

4. Coronavirus disease 2019 (COVID-19) Daily Reports. The Ministry of Health, Turkey. Available via https://covid19.saglik.gov.tr . Accessed 01 Jun 2020

5. World Health Organization website. Coronavirus disease 2019 (COVID-19) situation report-131. World Health Organization, Geneva. Available via https://www.who.int/docs/defaultsource/coronaviruse/situation-reports/20200601-covid-19-sitrep133.pdf?sfvrsn=9a56f2ac 4 . Accessed 01 Jun 2020

6. Huang P, Liu T, Huang L, Liu H, Lei M, Wangdong X, et al. Use of chest CT in combination with negative RT-PCR assay for the 2019 novel coronavirus but high clinical suspicion. Radiology 2020;295:22-3.

7. Xie X, Zhong Z, Zhao W, Zheng C, Wang F, Liu J. Chest CT for typical coronavirus disease 2019 (COVID-19) pneumonia: relationship to negative RT-PCR testing. Radiology 2020;296:E41-5.

8. Pan Y, Guan H, Zhou S, Wang Y, Li Q, Zhu T, et al. Initial CT findings and temporal changes in patients with the novel coronavirus pneumonia (2019-nCoV): a study of 63 patients in Wuhan, China. Eur Radiol 2020;30:3306-9.

9. Ai T, Yang Z, Hou H, Zhan C, Chen C, Lv W, et al. Correlation of chest CT and RT-PCR testing in coronavirus disease 2019 (COVID-19) in China: a report of 1014 cases. Radiology 2020;296:E32-40.

10. CDC COVID-19 Resonse Team: Bialek S, Boundy E, Bowen V, Chow N, Cohn A, Dowling N, et al. Severe outcomes among patients with coronavirus disease 2019 (COVID-19) - United States, February 12-March 16, 2020. MMWR Morb Mortal Wkly Rep 2020;69:343-6.

11. Yang J, Zheng Y, Gou X, Pu K, Chen Z, Guo Q, et al. Prevalence of comorbidities in the novel Wuhan coronavirus (COVID19) infection: a systematic review and meta-analysis. Int J Infect Dis 2020;94:91-5.

12. Wang Y, Dong C, Hu Y, Li C, Ren Q, Zhang X, et al. Tempo- 
ral changes of CT findings in 90 patients with COVID-19 pneumonia: a longitudinal study. Radiology 2020;296:E55-64.

13. Hansell DM, Bankier AA, MacMahon H, McLoud TC, Müller NL, Remy J. Fleischner Society: glossary of terms for thoracic imaging. Radiology 2008;246:697-722.

14. Ojha V, Mani A, Pandey NN, Sharma S, Kumar S. CT in coronavirus disease 2019 (COVID-19): a systematic review of chest CT findings in 4410 adult patients. Eur Radiol 2020;30:6129-38.

15. Ajlan AM, Ahyad RA, Jamjoom LG, Alharthy A, Madani TA. Middle east respiratory syndrome coronavirus (MERS-CoV) infection: chest CT findings. AJR 2014; 203:778-82.

16. Zhao W, Zhong Z, Xie X, Yu Q, Liu J. Relation between chest CT findings and clinical conditions of coronavirus disease (COVID-19) pneumonia: a multicenter study AJR 2020;214:1072-7.

17. Xu B, Xing Y, Peng J, Zheng Z, Tang W, Sun Y, et al. Chest CT for detecting COVID-19:a systematic review and meta-analyis of diagnostic accuracy. Eur Radiol 2020;30:5720-7.

18. Wan S, Li M, Ye Z, Yang C, Cai Q, Duan S, et al. CT manifestations and clinical characteristics of 1115 patients with coronavirus disease 2019 (COVID-19): a systematic review and meta-analyis. Acad Radiol 2020;27:910-21.

19. Ufuk F, Savas R. Chest CT features of the novel coronavirus disease (COVID-19). Turk J Med Sci 2020;50:664-78.

20. Xu Z, Pan A, Zhou H. Rare CT feature in a COVID-19 pa- tient: cavitation. Diagn Interv Radiol 2020;26:380-1.

21. Aydın S, Oz G, Dumanlı A, Balcı A, Gencer A. A case of spontaneous pneumothorax in COVID-19 pneumonia. J Surg Resh 2020;3:96-101.

22. Meng H, Xiong R, He R, Lin W, Hao B, Zhang L, et al. CT imaging and clinical course of asymptomatic cases with COVID19 pneumonia at admission in Wuhan, China. J Infect 2020;81:e33-9.

23. Cinkooglu A, Hepdurgun C, Bayraktaroglu S, Ceylan N, Savas R. CT imaging features of COVID-19 pneumonia: initial experience from Turkey. Diagn Interv Radiol 2020;26:308-14.

24. Li K, Wu J, Wu F, Guo D, Chen L, Fang Z, et al. The clinical and chest CT features associated with severe and critical COVID19 pneumonia. Invest Radiol 2020;55:327-31.

25. Zhou F, Yu T, Du R, Fan G, Liu Y, Liu Z, et al. Clinical course and risk factors for mortality of adult inpatients with COVID-19 in Wuhan, China: a retrospective cohort study. Lancet 2020;395:1054-62.

26. Wang B, Li R, Lu Z, Huang Y. Does comorbidity increase the risk of patients with COVID-19:evidence from meta-analysis. Aging 2020;12:6049-57.

27. Liu F, Zhang Q, Huang C, Shi C, Wang L, Shi N, et al. CT quantification of pneumonia lesions in early days predicts progression to severe illness in a cohort of COVID-19 patients. Theranostics 2020;10:5613:22. 